\title{
REVIEW OF STUDIES ON ORAL CASE PRESENTATIONS IN CLINICAL SETTINGS
}

\section{Nur Farah Fadhliah Mahmud, Afida Mohamad Ali (corresponding), Chan Mei Yuit}

University Putra Malaysia, Selangor, Malaysia

\begin{abstract}
Recent years have evidently shown that genre studies are growing considerably in language studies, mainly in the study of academic and professional genre. A number of academic genres have been focusing on the analysis of structural elements in research articles and theses' introduction. However, very few studies have attempted to examine the structural elements in professional genres, especially in medical academic setting. Due to the importance of this professional genre, particularly towards novices in order to improve their communication skills in presenting medical cases to their instructors or superiors, this paper reviews past studies related to genre analysis of oral case presentations in their academic and professional settings. By doing so, it reaches the conclusion that there are generic elements in oral case presentations that can guide medical novices to improve their way of presenting case presentations in medical academic settings.
\end{abstract}

Keywords: GENRE STUDIES, COMMUNICATION SKILL, ORAL CASE PRESENTATIONS

\section{INTRODUCTION}

Many studies have been done on communication among physicians, especially in the context of physician-patient communication, but few on physician-physician communication (Caldicott, 1998). Due to the potential in analysing the importance of presenting oral medical report or oral case presentation (OCP) especially among novices, researches and articles have touched on communication skills of physicians (Arluke, 1980; Evans, Wood \& Roberts, 2004; Tavakol et al., 2005; Cegala \& Broz, 2002) and medical discourse and structure in OCP (Anspach, 1989; Chacko et al., 2007; Davenport et al., 2008; Dell et al., 2012; Green et al., 2005).

Over the past century there has been a dramatic increase in researches on medical language, mainly on written medical journals and case reports (Adams-Smith, 1984; Mott, 1986; Salager-Meyer, 1992, 1994, 2001; Thomas \& Hawes, 1994; Nwogu, 1997; Varttala, 1999; McCarthy \& Reilly, 2000; Sutton, 2000; Wright \& Houroukis, 2000; Cohen, 2006; Aitken \& Marshall, 2007; Rezaee \& Sayfouri, 2009; Cianflone, 2011; Hung et.al., 2012) and doctor-patient communication (Beaulieu et al., 2011; Cegala \& Broz, 2002; Ford et al., 1996; Johanson et al., 1998; Kalitzkus \& Matthiessen, 2012; Mead \& Bower, 2000; Mickel, et al., 2013; Olson \& Windish, 2010; Roberts \& Sarangi, 2005; Robins \& Wolf, 1988; Tarn et al., 2006). 


\section{REVIEW OF STUDIES ON ORAL CASE PRESENTATIONS IN CLINICAL SETTINGS}

This paper concentrates more on the OCP genre by looking at the communicative purposes in medical OCPs, both in the academic or professional setting. It contributes to the outcome of communicative purposes, especially in providing needs towards medical students, either in their undergraduate or postgraduate studies. OCP is an act of presenting patients' health information from one doctor to another doctor, and the topic of presentation is mainly to discuss patients' health problems and investigations.

Historically, there has been limited literature on how the genre of oral case presentation emerged. The appearance of oral case presentation originated from patient's narratives which were found in 1984 by Erasmus Fenner. Fenner, who was the dean of the New Orleans Medical School during that period, required medical students to read patient's write-up case to medical professors on rounds (Davenport et al., 2008). According to Davenport et al. (2008), patient narrative was developed from the written case report due to its structural similarities. Even though medical case reports are illustrated in written academic discourse, they hypothesized that the format of oral presentation follows the same format as the written medical record. However, the oral presentation gives more attention on the information related to patient's chief complaint (CC).

The chronological order on how a patient's case is presented from one doctor to another doctor is basically based on the patient's stories. Upon admission to the hospital, a patient usually complains about his or her health condition to their respective doctor. Naturally, patients want their physician to understand their health problem, and treat their medical condition (Charon, 2001). This understanding requires the use of narrative competence, which is one of the competences that needs to be mastered by a physician. It involves skills of recognizing, absorbing, interpreting and lastly, responding to stories of illness. Transforming the stories from the patient's words into biomedical language is called narrative medicine. Past studies argued that in presenting case presentations, physicians typically translate patient's chief complaint into scientific medical language. This banishes the voice of the patient, which can lead to an incorrect diagnosis and loss of important information (Donnelly, 1997).

In relation to this, Hunter (1991) looked at how physicians interpret patients' stories regarding their health condition upon admission into their knowledge of practice. Here, she stated that it is a "medicine's principal way of applying its abstract knowledge to the care of the individual patient" (p.47). Once the physicians receive stories from their patients, they will clerk the case into a general template called case report, which constitutes a chief complaint, history of present illness, past medical history, personal and social history, family history, drug history, physical examination, laboratory and diagnostic findings data, summary statement, assessment, plan and medical records after discharge (Dell et al., 2012; Hung et al., 2012; Anspach, 1989; Maddow et al., 2003; Davenport et al., 2008).

By looking at the intricacies of how a patient case report is managed, it certainly requires a systematic and guided way of learning such skills. However, a major problem with this is if the OCP is poorly taught in medical schools (Kroenke, 1985). This indicates a need whereby medical students recognize the necessity to communicate professionally in English in order to present their patients' cases to the respective medical educators. Antic (2007) added that medical students have specific 


\section{REVIEW OF STUDIES ON ORAL CASE PRESENTATIONS IN CLINICAL SETTINGS}

demands of English language. They not only demand English in their healthcare interaction, but also to publish medical articles and to participate in international medical conferences.

\section{GENRE STUDIES}

Since the OCP is a type of genre in the medical field, it is wise to have a brief background of genre and genre studies. Genre studies have been developing rapidly in recent years, especially in investigating the rhetorical structure of a discourse. There are three main approaches to genre, namely Systemic Functional Linguistics, the New Rhetoric and English for Specific Purposes. The ESP approach to genre provides and recognizes Swalesian definition of genre as "...a class of communicative events, the members of which share some set of communicative purposes. These purposes are recognised by the expert members of the parent discourse community, and thereby constitute the rationale of the genre. This rationale shapes the schematic structure of the discourse and influences and constrains choice of content and style" (Swales, 1990:58). Genre analysis is an approach that has a reliable pedagogical rhetorical-functional framework, especially for novices and those who are facing difficulties to understand and be aware of the text characteristics.

Theoretically, genre analysis focuses on the identification of prototypical moves or functional components of a discourse (Jian, 2010). While Swales highlights the definition of academic genre, Bhatia (1993) concentrates more on genre in professional settings. Bhatia described genre as communicative practices with communicative purposes with allowable constraints. Allowable constraints here signify specialized structures and templates which occur in a specific discipline. The communicative purposes of a genre may influence the schematic structure of a text and simultaneously contributes to the internal structure of a text such as the choice of words used to describe the communicative event in a sentence.

This paper shall henceforth review studies conducted on OCPs from a genre perspective, identifying the limitations in previous studies and providing insights for further research.

\section{STUDIES ON THE GENRE OF ORAL CASE PRESENTATION}

This section is presented in five sections. Studies are specified according to the topic related to the genre of OCPs, which are (i) physicians' language and communication skills (ii) rhetorical moves and structures (iii) medical language and communicative approach (iv) perceptions and needs and (v) studies done in Malaysia.

\section{Studies done on physicians' language and communication skills}

Studies have shown that even though medical OCPs are highly structured with their own communicative purposes, students tend to make mistakes in their OCPs by producing irrelevant and unreliable information regarding patients' healthcare conditions in the Malaysian context, university students of Second Language Acquisition (SLA) have been struggling to produce "error-free language structures" (Ainon Jariah Muhamad et al., 2013). Since English language is the core language used in medical contexts, especially in terms of the interaction between students and their 


\section{REVIEW OF STUDIES ON ORAL CASE PRESENTATIONS IN CLINICAL SETTINGS}

seniors, students seem to struggle in communicating using good and grammatical English throughout their years of studies in medical field.

Apart from Malaysia, Chatterjee and Choudhury (2011) signified that communication skills training in India have not been covered well, especially among undergraduates and postgraduates. They proposed some benefits of using proper communication skills and suggested a framework to train medical educators. Also, they indicated some barriers in Indian medical education which were (a) language and educational barriers and (b) cultural and social diversity e.g. listening skills, speaking skills and interacting with patients regarding their verbalized frustration. These skills could overcome and encounter barriers of communication skills among physicians. They recommended in depth mandatory communication skills training courses to be taught regarding all topics to the undergraduates and postgraduates in India, using various teaching methods such as videos, role plays and didactic lectures within at least 3 days or more. This article did not include any research design or research outcomes, yet it was more on proposing some ideas that could be implemented by medical educators. The ideas mentioned could be adapted and applied in any medical educational settings worldwide.

In contrast to the previous study, Stausmire et al. (2014) measured general surgery residents' communication skills from the patients' perspectives using Communication Assessment Tool (CAT). This study was qualitative in nature, using a 14-item paper version with a 5-point rating scale adapted from Makoul et al. (2010) which was seen to be a reliable and valid instrument to measure patients' perceptions of physicians' interpersonal and communication skills. However, the researchers highlighted one limitation of using CAT in patients' satisfaction measurement, whereby only the scores of "excellent" (equalled a yes) rated by patients can be counted to detect the differences of communication skills among physicians. Thus, this shows that CAT does not accurately count other scores, for instance, "very good, good, fair, and poor" (equalled a no). The respondents included males and females from various ethnicities and different age groups. They had to rate the interpersonal communication skills of 17 general surgery residents cum postgraduate students from Osteopathic department. The researchers ruled out some limitations of the study due to the use of a single general surgery residency program only. However, there were recommendations suggested to future studies especially in applying the same research design to other specializations in medical setting.

Another different study was done by Cegala and Broz (2002). They did a medical literature review through Medline search published from 1990 till present to broaden the critiques that were made by Huslmen et al. in 1999 regarding the development and implementation of communication skills training programmes among physicians. They argued that most studies used inadequate research designs and the behavioural effects can only be generalized to certain target communication behaviours only. Therefore, Cegala and Broz provided some additional direction to future researchers regarding this issue. They recommended some alternatives with more direct implications to improve the quality of training research in terms of the assessment instruments and conceptual and methodological issues. These two recommendations should be in line with the communication skills taught to the participants so that adherent skills could be implemented wisely. This kind of study had 


\section{REVIEW OF STUDIES ON ORAL CASE PRESENTATIONS IN CLINICAL SETTINGS}

simultaneously given highlights on what studies had been done previously in relation to doctors' communication skills. A thorough literature review could provide future researchers on what had been done and what designs could be adapted and suitable for their upcoming researches, hence giving better results for their studies. Ishikawa et al. (2014) did a pilot study at one of the universities in Japan to discover resident physicians' attitudes and confidence in communicating with patients. Basically, they wanted to explore the physicians' confidence in conducting medical interviews and its relationship with their attitude in patient-physician interaction, along with their previous experience of communication skills training at medical schools in Japan. The study was done quantitatively by distributing questionnaires to 72 resident physicians. However, only 67 questionnaires with completed consent forms were received. Overall, data were calculated through Cronbach's $\alpha$ coefficients for internal consistency and analyses were done using Stata 12.0 software. Results showed that resident physicians had high confidence in gathering information and building a relationship but less confidence in sharing information and planning treatment with other residents. The investigators highlighted some recommendations for future researchers as in to investigate more on resident physicians' attitudes toward patient-physician relationship, and whether it could influence the process of learning the communication skills needed for medical interviews or vice versa.

Ishikawa et al. (2014) claimed that medical interviews required three skills, namely (1) to gather data to understand patients' problems, (2) to develop rapport and respond to patients' emotions, and (3) to encourage patients to adhere to treatment recommendations. These three skills were essential in demonstrating resident physicians' competence in applying their communication skills regarding clinical situations whichever relevant to their specialties. Some limitations were addressed especially on the sample study which represented only Japanese sociocultural context. However, they strongly claimed that the results were consistent with the studies that had been done in the United States. No inter-rater reliability was mentioned in this study.

As a whole, communication skills among physicians, especially medical novices are important as it can be regarded as the heart of the medical education. By applying good communication skill with patients, they can confidently give their best in giving presentations to their colleagues or supervisors regarding patients' healthcare planning and treatment. This activity, better known as medical or oral case presentations (OCP), requires full attention in giving history of present illnesses, chief complaints, past medical, social and family histories, current treatments and recommendations. Some of the studies that have been done on the structure of OCP can be reviewed in the next sub-topic.

\section{Studies done on rhetorical moves and structures in oral case presentations}

\section{Rhetorical moves in OCPs}

Many studies have been conducted on the rhetorical moves of medical written genre such as medical research articles and medical journals. However, compared to the written genre, studies on the rhetorical moves of medical oral genre have not been treated in much detail. Dell, Lewin and Gigante (2012) signified expectations of medical trainers toward their students in oral case presentations. They focused on the characteristics of high-quality oral presentations by medical students. They 


\section{REVIEW OF STUDIES ON ORAL CASE PRESENTATIONS IN CLINICAL SETTINGS}

provided an oral case presentation expectations checklist which have seven schematic structure or moves in OCP which are (1) Chief complaint, (2) History of present illness, (3) Physical examination, (4) Laboratory data, (5) Summary statement, (6) Assessment and (7) Plan. The checklist was given as a reference for medical students to provide an organized case presentation in terms of what to say and what not to say. This checklist may be adapted by researchers in the same scope of study, and not limited to those from United States of America only, but also to all researchers from all over the world, particularly researchers who are interested in the structure of OCPs by medical students.

Maddow et al. (2003) investigated the effectiveness of assessment-oriented (AO) OCP as a model of inter-physician communication. They argued a traditional format of OCP consists of seven moves which are chief complaint, history of present illness, past medical, social and family histories, physical examination, ancillary data, assessment and plan. In their study, they signified two OCP templates which are traditional template and AO template. The suitability of AO has been recognized in Emergency Department (ED) because it has moves such as patient identification, assessment and management/therapeutic plan, limited justification of the assessment and plan based on historical and examination information because it was $40 \%$ shorter with time savings of 46 seconds. No research design was mentioned. However, it can be assumed that ethnography study was applied whereby a research assistant and principal investigator participated in an intensive workshop with the residents. 199 OCPs were quantitatively analysed using standard descriptive statistics. From this study, it is believed that the traditional format of OCP includes unnecessary information which simultaneously misdirects and confuses clinicians. Extrinsic factors might have influenced the results and this has become one of the limitations in this study. Finally, it can be summed up that this study highlighted the importance of inserting necessary information guided by AO template so that clinicians can 'get to the point' in OCP without losing any significant content or organization.

In contrast to the study above, Green et al. (2005) claimed that their creation of multifaceted intervention of OCP could improve medical students and internal medicine residents' OCP. They suggested guidelines and created standards for OCP by providing written handout with detailed instructions, pocket cards, model presentations and multiple teaching sessions. The researchers also gave detailed contents in each intervention, which gave a clear picture on what should be expected from the novices in their OCPs. The sampling was a convenience sampling and the data of feedbacks were quantitatively analysed. The procedures were done in various clinical and classroom academic settings whereby the researchers distributed the guidelines at the beginning of the students' ward rotation, at conferences during internal medicine rotation and during OCP exercises. The instructions for the students to follow abridged instructions for OCPs of new patients on work rounds were created after thorough analyses done on the issues regarding OCPs by Haber and Lingard (1999, 2001), Kroenke (1985), Wiese et al. (2002) and Wiese et al. (2002). The suggested guidelines of OCPs revealed that medical students were expected to follow a nine-move pattern consisting of overview, opening statement, source, present illness, other history, physical exam, labs/data, synthesis and enumerated problem list. After the analysis of the data, they defined the importance of 


\section{REVIEW OF STUDIES ON ORAL CASE PRESENTATIONS IN CLINICAL SETTINGS}

OCP and the need in creating and developing a standard OCP guideline as it will reduce variability in academic assessment by their educators.

Schryer et al. (2003), on the other hand, investigated structure and agency in medical case presentations. The study applied grounded theory and statistical strategies to look upon the genre. They transcribed 16 OCPs by third year medical students in a children's hospital. The structure and agency in this study signified educational abilities in problem-solving while presenting OCPs. Data was collected through two phases which were (1) field observations which involved audio recording and transcribing by 11 students and 10 faculty members and (2) 45 -minutes interviews by 11 students and 10 faculty members. Data were analysed using NVivo qualitative data analysis software. As a result, there were three situations that occurred during the OCPs of the students. However, the most notable result which appeared to be associated to the structure of OCP was seen in the first situation, whereby the OCP session was observed to be a regularized interaction between students and doctors. There were two patterns of regulations which were (1) case format and (2) control of time. These patterns seemed to be highly regularized and the students recognized and self-regulated the structure of OCP. It was well known by the students to follow the flow of OCP which consisted of identifying the patient, history of present illness, past medical history, social history, etc. They claimed that the 'template' of OCP would keep them on track throughout their presentation. However, the study was limited to only one sample in a children's hospital. In sum, the analysis did not reveal any significant moves in the regularized interaction between students and their mentors in the OCP.

\section{Structures in OCP}

Studies on the structure of OCP highlighted the preceptors' effective strategies in teaching clinical knowledge to the juniors. Generally, preceptors are medical providers who teach and give medical learners practical skills, particularly related to real-world training during their academic appointments. According to MAHEC (Mountain Area Health Education Center) and Alguire et al. (2001), preceptors demonstrate effective communication skills such as (1) possessing and demonstrating broad knowledge; (2) explaining the basis for actions and decisions; (3) answering learner's questions clearly and precisely; (4) being open to conflicting ideas and opinions; (5) connecting information to broader concepts; (6) capturing learners attention and (7) making learning fun. In general, the structure in OCP such as One-Minute Preceptor, Aunt Minnie and SNAPPS (Irby $\&$ Wilkerson, 2008) are the teaching strategies by the preceptors to be applied by the juniors in presenting patients' clinical history.

Irby, Aagaard and Teherani (2004) investigated the effectiveness of teaching points such as OneMinute Preceptor (OMP) and traditional precepting model (TP) in ambulatory teaching setting. The investigators examined both teaching scripts with their pros and cons for effective teaching strategy in clinical settings. In this study, they highlighted that OMP is purposeful in diagnosing both learners and patients, while TP focuses only in diagnosing the patient. OMP consists of 5 steps which are (i) getting a commitment, (ii) probing the underlying reasoning, (iii) teaching a general rule, (iv) providing positive feedback and (v) correcting mistakes. TP, on the other hand, does not reveal the 


\section{REVIEW OF STUDIES ON ORAL CASE PRESENTATIONS IN CLINICAL SETTINGS}

learner's cognitive skills as the preceptors will only ask about the problems and how to diagnose the patient. The investigators studied the effectiveness of both teaching points by videotaping medical students' case presentations using the two models. A convenience sampling was used which consisted of 116 participants. This study did not involve any outpatients in ambulatory setting. Overall, the investigators concluded that the preceptors shifted both teaching models in accordance to the case at hand. They were not rigid in their use of one teaching model in guiding students on how to present their case in medical setting.

Davenport, Honigman and Druck (2008) suggested an approach on how to educate medical students to give optimal OCP in emergency (EM) contexts. The moves in OCP only focused on history of present illnesses, medications, allergies, physical examinations and summary statements based on the evolution of SNAPPS in 2003. Wolpaw et al. (2003) defined SNAPPS as a learner-centered model for case presentation to the preceptor by following six steps. These six steps consist of (1) Summarizing briefly the history and findings; (2) Narrowing the differential to two or three relevant possibilities; (3) Analysing the differential by comparing and contrasting the possibilities; (4) Probing the preceptor by asking questions about uncertainties; (5) Planning management for the patient's medical issues; and (6) Selecting a case-related issue for self-directed learning. However, SNAPPS has been used a lot as an educational technique in Emergency Department as this mnemonic should not exceed six to seven minutes in length by highlighting the act of reporting facts and expressing students' thinking and reasoning (Wolpaw et al., 2003; Connell, et al., 1999). SNAPPS might assist the target in achieving a good delivery of patient's narrative not only in EM context, but also during round wards and in-class OCPs. There were no research methodology and data analysis mentioned. However, the researchers suggested recommendations which can be adapted by future researchers in considering the significance of the study to develop medical curriculum genre-based pedagogy.

\section{Studies done on medical language and communicative approach}

\section{Medical language}

In OCPs, medical language plays an important role in delivering information regarding patients' healthcare conditions. OCPs by medical students are filled with medical jargon and terminology, which can make them being realized as medical professionals. Despite rich literature existing on physician-patient communication, studies on medical language were done due to the awareness that physicians interact and communicate differently to their patients than they do among themselves. Also, the studies mentioned below showed the struggle of medical students in using proper language while presenting OCPs.

Caldicott (1998) examined medical trainees' verbal delivery in the setting of an inpatient medical service. Among the aspects eaxamined were dysfluency in discourse such as pauses, fillers, laughter, and self-interruptions of fluent speakers which can provide clues for detrimental conditions in medical education environment. It was a qualitative study with an 18-hour tape-recording of casual conversations and attending rounds on inpatient general medicine at a tertiary-care teaching hospital. The use of fieldnotes and transcribed audiotapes can provide an in-depth understanding about 


\section{REVIEW OF STUDIES ON ORAL CASE PRESENTATIONS IN CLINICAL SETTINGS}

dysfluency. This study is beneficial to researchers who are interested in looking at the communication skill among physicians only as it did not involve any patients in the data collection. The study applied content analysis and found that dysfluency is regarded as an important linguistic behaviour. Nonetheless, the investigator did not mention any significance of selecting the sample and nothing was mentioned about the reliability of the study.

An ethnography researcher, Anspach (1989) studied formal presentations of case histories by physicians in training to their superiors. The features of presentation were classified into four, which were the separation of biological processes from the person (depersonalization), omission of the agent (use of passive voice), treating medical technology as the agent and account markers ("states", "reports" and "denies" as to emphasize the subjectivity of patient accounts). The features of OCP might affect medical decision-making and highlight occupational registers which occurred in case history presentations. Observations and interviews were carried out with the participants to get a thorough data. Fifteen OCPs were collected selectively from two intensive care nurseries, and obstetrics and gynaecology specialization. The study was limited in terms of the data collection and the author did not mention any gap from previous studies.

Spafford et al. (2007) studied communicative features of clinical uncertainty of social work students and their supervisors. This study applied qualitative analysis method and analysed 186 pages of observation transcripts obtained from 16 participants' audio recordings. The study was enriched with 45-minute interview sessions done with the participants. Both observations of oral presentations and interviews were transcribed and participants remained anonymous. However, the authors did not mention strong arguments on how and why they selected the sample, yet they mentioned that the sample was similar to their past study (Schryer et al., 2003, 2005; Lingard et al., 2003a, 2003b; Spafford et al., 2004). . In this study, they described the flow of analysis and highlighted the emerged themes gathered using QSR NVivo qualitative data analysis software. From here, they concluded that there were five major themes which were (i) student strategies; (ii) professional strategies; (iii) teaching strategies; (iv) identity formation, and (v) case presentation format and record keeping strategies. However, they did not discuss any of the five major themes, notwithstanding with attitudes toward uncertainty and behaviours toward uncertainty. The results revealed no noticeable communicative features, such as lexical words that indicated clinical uncertainty. It was more on the behaviours toward uncertainty among medical students.

\section{Studies with various perspectives on OCP}

Medical students use various approaches in delivering effective OCPs to their senior lecturers. The approaches may reveal the strategies used by novices in presenting OCPs which simultaneously can bare novices' pragmatic intentions.

Schryer et al. (2003) discussed OCP as a mode of communication among physicians regarding prominent details of patient cases, primarily the one that occurred during hospital rounds and at the same time argued the plans and managements that could be addressed in relation to the ailments. They signified a study concerning structure and agency in OCPs and conducted an ethnography 


\section{REVIEW OF STUDIES ON ORAL CASE PRESENTATIONS IN CLINICAL SETTINGS}

research via field observations and interviews towards third-year medical students, specifically in Department of Paediatrics. By using modified grounded theory and statistical strategies in analysing data, they found out that the genre of OCPs functioned as mediating tools that allow medical experts to negotiate agency across generations and levels of expertise as sets of strategic choices. The investigators transcribed 16 OCPs and conducted two interviews, which they turned into scripts, dramas and videotapes. The overall outcome highlighted that the identification of structure and agency in OCPs opens up learning strategies and behaviours for medical students to communicate effectively to their patients. Yet, from the results and discussion, the researchers did not identify what kind of agency occurred in the presentations and simultaneously led to confusion in understanding the appropriate meaning of agency within medical context. To sum up the study, results were discussed and related to the importance and perspectives towards medical case presentations' structure by medical students.

Spafford et al. (2004) claimed that OCP is commonly used in health professions to shape novices' sense of professional identity through the teaching of standards of practice. This qualitative research made use of field observations from 31 OCPs by 8 optometry students and 6 faculty optometrists. Also, the researcher interviewed 4 optometry students and 4 faculty optometrists regarding the nature and purpose of OCPs in the Primary Care rotation. It was clearly mentioned that the interviewees were selected from a convenience sampling. 137 pages of transcriptions were analysed and coded using QSR NVivo qualitative data analysis software. Results showed that there are five moves or strategies namely (1) Student Strategies, (2) Doctor Strategies, (3) Case Presentation and RecordKeeping Strategies, (4) Teaching Strategies and (5) Identity Formation. In general, those five moves had been previously characterized in their previous researches in 2003 (Lingard et al., 2003) and 2004 (Schryer et al., 2004). The study revealed that there were three approaches in the standards of practice towards optometry students which are the Official Way, Our Way and My Way. The study was limited to one group of medical professionals, therefore it cannot be generalized that all medical professionals use the same standard of practice. However, the results of the study showed that both novices and senior lecturers have their own distinctive communicative strategies in revealing their pragmatic intentions regarding OCPs. Last but not least, nothing was mentioned about the reliability of analyses.

Lingard and Haber (1999) studied 'relevance' in medical case presentations. 'Relevance' here means the act of filtering nonessential data from case presentations. This is related to the discourse strategy used in presenting a medical case. This study was done due to some claims made by both physicians and students that they faced difficulties to determine relevance. They conducted a qualitative study on case presentations done by third year students and physician teachers in 1996 and 1997, using nonparticipant observations. Data were gathered through observation notes, interview transcripts and survey responses particularly from students, faculty and curriculum documents. Triangulated data were analysed using grounded theory technique and categories were generated to represent trends in the data, which are The Principle of Relevance and The Phenomenon of Presupposed Knowledge. The first trend revealed the emergence of presupposition in the spoken reference to relevance, while the later trend showed there are pragmatic features in the students' grammatical structure. As a 


\section{REVIEW OF STUDIES ON ORAL CASE PRESENTATIONS IN CLINICAL SETTINGS}

whole, this study contributes to a greater need for students to determine relevance in their cognitive knowledge so that they know which trend to be used while doing presentations. For example, what is relevant to request a specialty procedure and what is relevant to update the attending physician, without changing the patient's clinical status. The authors did not mention any gaps in previous studies with regard to this issue at hand and no specific reasons were stated for the selection of sample.

Spafford et al. (2007), too, analysed the discourse of uncertainty by medical students in transmitting clients' information to their expert supervisors. They studied communicative features of certainty and uncertainty in novice social work supervision and examined how those features contributed to the development of professional identity in social work students. Other than that, they defined what are meant by uncertainty, professional socialization and identity formation and case presentations in communication practices, which were found effective in giving introductory information on what the study was about. The authors highlighted the gap from their past study of medical and optometry students where it only focussed on personal deficit and a distrust of acknowledging uncertainty. The analysis revealed that there are various behaviours toward uncertainty which were (i) seeking guidance, (ii) deflecting criticism, (iii) owning limits and (iv) showing competence. Their findings also affirmed the rhetoric of uncertainty shown by three types of professional students. However, this study lacked examples on lexical features used to determine the act of uncertainty in delivering case presentations. Furthermore, the reliability of analysis was not discussed.

Shi et al., (2001) analysed linguistic skills using medical students' performance data to develop an English course for clinical training. They conducted an ethnography study whereby they observed and videotaped 5 and audiotaped 1 session of students' bedside performance in ward teaching, particularly on the discourse features in their verbatim transcriptions to develop English teaching materials. The study was limited to speaking skills between student and tutor in medical communication. The authors detailed out the process of transcribing the recordings. Not only that, they managed to develop a coding scheme to cover the topics of the discourse and illustrated it into table. The language used was easy and can be understood. Nonetheless, there was no gap from previous study being mentioned with regard to this issue, regardless of a brief history about the background of English language in Hong Kong. After they analysed the data, they developed a curriculum to improve the communication skills of students who were in their first phase of clinical training. They came out with a dimension of task design for clinical communication course. From here, it can be noted that the authors undergo several stages in developing a curriculum: (i) needs analysis, (ii) curriculum specification, (iii) materials writing, teaching and evaluation and (iv) preliminary revision of the course materials. Future recommendations were suggested to future researchers to adopt similar approaches to help in students' writing skills.

\section{Studies done on perceptions and needs towards oral case presentations}

Lingard et al. (2003b) investigated the genre of OCP as a medium of socialization into the clinical community of practice between medical students and faculty members. The objective is to know how learning environment aided by OCP can help novices reach the values and goals of health profession discipline. To achieve the objective, this study involved an observation of 16 OCPs and teaching 


\section{REVIEW OF STUDIES ON ORAL CASE PRESENTATIONS IN CLINICAL SETTINGS}

environments during inpatient paediatric medicine rounds. A triangulation of data was done by interviewing 11 students and 10 faculty members. The OCPs were audio-recorded, transcribed and analysed in order to get emergent themes and rhetorical strategies through NVivo qualitative data analysis software. Results showed that students and faculty members perceived OCP as 2 different strategy dimensions of thinking, which are 'strategizing as a student' and 'strategizing as a doctor'. The students always perceive and perform an ideal school genre while the doctors always perceive their performance in OCPs to be of a workplace genre. Here, students are often trying to avoid uncertainty in their OCP as to prove their competence, minimize interruption and deflect criticism whereas the faculty wants the students to have access to relevant and reliable data information regarding patients' health care conditions. This study gives a clear picture that novices and doctors have different views on how they perceive OCP. However, there was nothing mentioned about the reliability of the analysis.

Chia et al. (1999), in a survey study, singled out two questionnaires to generally describe the perceptions of 349 medical students from Department of Medicine and 20 faculty members for their English language needs based on survey instruments by Zughoul \& Hussein (1985) and Guo (1989). However, there were no justifications provided for the choice of method and the reasons why they chose the sample. Likewise, the authors did not mention any gap from previous studies with regard to the issue of language needs in Taiwan. The study was conducted to suggest requisites for English language curricula based on the survey results. Also, it was done due to the awareness that some colleges are in the process of developing specific English courses, via conducting needs analysis. SPSS program was used for data analysis where Chi-square, t-tests and ANOVA analyses were done to determine the perceptions of English language needs by medical college students and their faculty, and to compare the perceptions with three various groups; (i) the lower class men, (ii) the upper class men and (iii) the faculty. As a whole, both students and faculty perceived English courses as a requirement. However, the researchers argued the present method for teaching English which was Grammar Translation Method did not meet students' need for higher proficiency of English skills particularly in listening. They recommended techniques such as role-playing and problem solving to be used in English courses to improve students' proficiency in aural and oral skills. Also, they made some suggestions that research on English language needs should be discovered in order to expand ESP language programs in higher education. These recommendations affirmed the fact that needs analysis could develop English proficiency in students' academic and professional needs.

Hwang and Lin (2010) discovered linguistic needs and perceptions of medical students and faculty members in Taiwan in a study conducted on 378 medical students from Department of Medicine at Chung Shan Medical University. The samples were selected from 117 freshmen, 79 sophomores, 59 juniors, 79 seniors, 44 fifth grades and 24 faculty members. This study was analysed quantitatively using questionnaires through descriptive statistics. Moreover, Chi-square and one-way ANOVA analyses were also conducted to determine the perceptions on linguistics needs among medical students and also to compare the perceptions held by the three groups which were (1) faculty, (2) lower class group and (3) upper class group. This study was done quantitatively as it consisted of a 


\section{REVIEW OF STUDIES ON ORAL CASE PRESENTATIONS IN CLINICAL SETTINGS}

large number of samples. However, it can be tailored in terms of the aims in looking at the linguistic needs preferred by medical students for both current studies and future careers.

Dell, Lewin and Gigante (2012) wrote an article that signified expectations of medical trainers for students in presenting oral case presentations. The article focused on teaching and evaluating the presentation skills by applying the characteristics of high-quality oral presentations. The authors provided checklist of oral presentation expectations by medical trainers and highlighted RIME scheme as one of the effective ways to assess medical students' presentations. Due to the nature of this written work as an article, it did not mention any methodology or findings. Therefore, the authors did not include any data that showed medical students' assessments towards the presentations.

Dafa-Allah (2012) investigated ESP learners' needs among medicine students at Sudanese Universities and found out that there were three types of learners' needs, which were English Language for general purposes, academic purposes and job purposes. The study was done quantitatively whereby the data was collected in the format of questionnaire and was given to 300 students within three different universities in Sudan. The questionnaire had been assorted under three main types, which were general needs, academic needs and job needs, and sought to collect information concerning the immediate and long-term perceived needs among students who studied medicine through an English medium of instruction. From here, the students identified the need for English in their medical discipline and also gave feedback on which skills of language they needed for their academic purposes. The results showed that the students needed English more on academic needs rather than jobs needs and general needs. The students need English to understand lectures and to write answers to examinations questions. However, the least that can be seen from the study was they do not perceive English as an important subject during the in-service courses, which were conducted in English.

\section{Studies done in Malaysia}

Few studies have been done on oral case presentations, particularly on the moves, structures and language perspectives in Malaysia. A large number of studies was found on communication skills implied by medical students, especially in breaking bad news to patients or their relatives. However, due to this limitation, it is best to make a review on the studies done in Malaysia in relation to medical students as this will give some insights towards Malaysian researchers to expand their studies in multidisciplinary areas.

Al-Dubai et al. (2011) studied the perception of stress and the strategies in coping with stress among Malaysian Management and Science University (MSU) undergraduate medical students. It was done based on a review of past stress-related studies in Nepal, Sweden, Pakistan, United Kingdom and Malaysia. A cross-sectional survey using Likert-scale questionnaire was distributed to 372 medical and medical sciences students. However, the authors did not include the reasons why these samples were chosen and how the method of sampling was chosen. This study found out that there was an association between perceived stress and coping strategies. Nevertheless, this study was only a snapshot of MSU medical undergraduates, for it did not represent the whole students in Malaysia. Then again, this study included a definition on stress, which gave a better understanding to readers, 


\section{REVIEW OF STUDIES ON ORAL CASE PRESENTATIONS IN CLINICAL SETTINGS}

especially social science researchers. The gap in previous studies was mentioned as negligence about perception of stress among medical students and their coping strategies. The authors recommended future researchers to follow-up in a longitudinal study in order to achieve a reliable data on stress.

Khan et al. (2009) studied the importance of communication skills among postgraduate medical students in Malaysia. The purpose of analysis was to quantify the current knowledge of postgraduate (PG) medical students in Malaysia regarding the importance of communication skills. These may simultaneously help improve their professional skills and handling patients. To fulfil this purpose, the study used a cross-sectional survey of 154 self-report questionnaires. The gap was clearly identified as there was less attention given to communication skills in the practice and training of doctors in Malaysia. Nonetheless, the analyses were more on identical differences between male and female postgraduate students in relation to their communication skills. No explanation was given on the reasons why postgraduate students were chosen to be part of the sample. The authors recommended some suggestions for future researchers to focus more on developing communication skills throughout medical curriculum as Malaysian medical students' have poor confidence level in communicating with patients or senior doctors. The limitations of this study were clearly highlighted to the extent that this study cannot be generalized as it was done one particular medical school only.

Another study which focused on communication skills among Malaysian medical students was conducted by Ullah et al. (2012). They studied the validity of communication skills attitude scale among Malaysian undergraduate medical students. The purpose of the study was to check the validity and reliability of CSAS (Communication Skills Attitude Scale). The authors' explanation on the reasons why this study was carried out was clear, short and direct. However, the overall clarification on methodology, results and discussions were confusing as they were explained without any tables or graphs. The consistency on the reliability of CSAS was established through internal consistency reliability, which was one of the types of reliability.

Abdus Salam et al. (2008) studied perceptions of communication skills among UKM (Universiti Kebangsaan Malaysia) medical graduates during their housemanship. The gap of the study was signified based on past studies done in 1992, 1995, 2003 and 2006, especially regarding doctors' interpersonal and communication skills. A cross-sectional study was carried out on 172 house officers who graduated from UKM in 2004 as in to determine their perceptions on the old curriculum on communication skills in different aspects. Open and close-ended questionnaires were distributed to the sample through home mail, but only 32 doctors responded and returned the questionnaire. The study findings were illustrated into two tables, together with percentages of ability or skills in (i) communication with different groups of people, which appeared in five sections: (1) peers, (2) support staff, (3) patients, (4) patients' family, (5) superiors and (ii) communication tasks; (1) breaking bad news, (2) counselling patients, (3) taking consents; these gave clear view on the results gathered from different variables. It is recognized that some words were grammatically incorrect as in 'pro-fessional' and 'com-munication'. This study did not reveal any data relating to open-ended questions and did not indicate any quantitative data analysis procedure, thus it can be summed up that the consistency of the findings were not reliable. 


\section{REVIEW OF STUDIES ON ORAL CASE PRESENTATIONS IN CLINICAL SETTINGS}

Chan (2012) also conducted a study on views of Malaysian interns and their supervisors regarding undergraduates' clinical skills training and whether it has adequately equipped them for internships or vice versa. Prior to the real study, a pilot study was carried out in order to pre-test the question items. To fulfil the objective in determining the views of Malaysian interns and their supervisors on whether undergraduate clinical skills training adequately equipped them for internship, he invited all Malaysian hospitals to participate in this study. However, only 22 out of 32 hospitals participated, with 521 participants (350 interns and 171 supervisors) completing the questionnaire. A Likert-scale questionnaire was used to assess the respondents' opinions on training skills along with demographic data. Three types of data analyses were used to determine the significant association between the variables and the respondents' views, particularly through SPSS, Chi-square tests and logistic regression. However, the result of the study was totally depended on the Likert-scale questionnaire. It is best to suggest that future research could add more reliable responses from the interns and their supervisors through interviews. This is because a Likert-scale questionnaire may be biased in terms of getting people's perceptions or views regarding their professional acts.

\section{CONCLUSION}

Based on the reading materials, it can be signified that many studies were done on the written genre of medical case presentations, such as medical journals and reports by applying Swales genre theory. Few studies were found to be using a genre framework in analysing the oral case presentation (OCP) particularly in academic or professional settings. In Malaysia too, although many researches have been carried out on the communication skills among medical novices and patients, there have been few empirical investigations on the generic structure of the OCP as used by novices or medical students. Medical students are still unsure of how to organize their OCPs coherently with essential information of their patients', which are needed in their profession. Therefore, it is argued that there should be a balance in studying and analysing the rhetorical structure of medical OCP and communication skills among physicians so that multidisciplinary studies can be developed in medical education, especially in Malaysia. The outcome of the studies mentioned above will be beneficial for medical pedagogy and can enhance the communication skills among novices and senior physicians as OCP is a crucial genre in the healthcare clinical setting. It is a vital professional activity among clinicians to transfer information regarding patients' illness in order to administer proper medication and treatment. Also, it is beneficial for medical novices to have the linguistic and professional competence regarding the healthcare analyses and discussions with their respective supervisors or educators.

\section{FURTHER STUDIES}

So far, very limited studies have been conducted using a genre analysis framework from these multidisciplinary specializations which are Medical and Linguistic, mainly on the rhetorical structure perspective. Also, the studies to date have focused on the written genre of medical case presentations from the western countries rather than the oral version of OCPs. Future studies on OCPs' generic structure need to focus more on the oral discourse of case presentations as present studies (Ishikawa et al., 2014; Eerwegh et al., 2014) have highlighted the importance of communication skills among 


\section{REVIEW OF STUDIES ON ORAL CASE PRESENTATIONS IN CLINICAL SETTINGS}

physicians, especially medical novices either in their interactions with their patients and also among physicians themselves.

\section{REFERENCE}

Adams-Smith, D. (1984). Medical discourse: aspects of author's comment. English for Specific Purposes, 3, 25-36.

Aitken, L. M., \& Marshall, A. P. (2007). Writing a case study: ensuring a meaningful contribution to the literature. Australian Critical Case, 20, 132-136.

Ainon Jariah Muhamad, Mohammed Ismail Ahamad Shah, Engku Haliza Engku Ibrahim, Sarudin, I., Faridah Abdul Malik, \& Rozina Abdul Ghani. (2013). Oral presentation errors of Malaysian students in an English for academic purposes (EAP) course. World Applied Science Journal, 21, 19-27.

Alguire, P. C., DeWitt, D. E., Pinsky, L. I., \& Ferenchick, G. S. (2001). Teaching in your office: a guide to instructing medical students and residents. Philadelphia: American College of Physicians.

Anspach, R. R. (1988). Notes on the sociology of medical discourse: the language of case presentation. Journal of Health and Social Behaviour, 29(4): 357-375.

Antic, Z. (2007). Forward in teaching English for medical purposes. Medicine and Biology, 14(3): 141-147.

Arluke, A. (1980). Roundmanship: inherent control on a medical teaching ward. Soc Sci \& Med, 14A, 297-302.

Arntfield, S. L., Slesar, K., Dickson, J., \& Charon, R. (2013). Narrative medicine as a means of training medical students toward residency competencies. Patient Education and Counseling, 91, 280-286.

Avegno, J. L., Murphy-Lavoie, H., Lofaso, D. P., \& Moreno- Walton, L. (2012). Medical students' perceptions of an emergency medicine clerkship: an analysis of self-assessment surveys. International Journal of Emergency Medicine, 5(25): 1-6.

Beaulieu, M-D., Haggerty, J. L., Beaulieu, C., Bouharaoui, F., Levesque, J-F., \& Pineault, R. (2011). Interpersonal communication from the patient perspective: comparison of primary healthcare evaluation instruments. Healthcare Policy, 7, 109-123.

Bhatia, V. K. (1993) Analysing Genre: language use in professional settings. London: Longman.

Caldicott, C. V. (1998). What's wrong with this medical student today? Dysfluency on inpatient rounds. Annals of Internal Medicine, 7(128): 607-610. 


\section{REVIEW OF STUDIES ON ORAL CASE PRESENTATIONS IN CLINICAL SETTINGS}

Cegala, D. J., \& Broz, S. L. (2002). Physician communication skills training: a review of theoretical backgrounds, objectives and skills. Medical Education, 36, 1004-1016.

Chacko, K. M., Aagard, E., \& Irby, D. (2007). Teaching models for outpatient medicine. The Clinical Teacher, 4, 82-86.

Chan, S. C. (2012). Views of Malaysian interns and their supervisors on the adequacy of undergraduate clinical skills training. Singapore Med J, 53(3): 196-202.

Charon, R. (2001). Narrative medicine: a model for empathy, reflection, profession, and trust, JAMA, 286 (12): 1897-1902.

Chatterjee, S., \& Choudhury, N. (2011). Medical communication skills training in the Indian setting: need of the hour. Asian J Transfus Sci, 5(1): 8-10.

Chia, H. U., Johnson, R., Chia, H. L., \& Olive, F. (1999). English for college students in Taiwan: a study of perceptions of English needs in a medical context. English for Specific Purposes, 18(2): 107-119.

Cianflone, E. (2011). Academic genres in EFL medical educational contexts: the medical case-report. Scripta Manent, 6(1-2): 2-8.

Cohen, H. (2006). How to write a patient case report. Am J Health-Syst Pharm, 63, 1888-1892.

Connell, K. L., Bordage, G., Chang, R. W., Howard, B. A., Sinacore, J. Measuring the promotion of thinking during precepting encounters in outpatient settings. Acad Med, 74(10): 10-12.

Dafa-Allah, F. (2012). ESP learners' needs: a case study of medicine students at some Sudanese universities. English for Specific Purposes World, 36(12): 1-16.

Davenport, C., Honigman, B. \& Druck, J. (2008). The 3-minute emergency medicine medical student presentation: a variation on a theme. Society for Academic Emergency Medicine, 15(7), 683 $-687$.

Dell, M., Lewin, L., \& Gigante, J. (2012). What's the story? Expectations for oral case presentations. Pediatrics 130(1): 1-4.

Donnelly, W. J. (1997). The language of medical case histories. Annals of Internal Medicine, 27(11): 1045-1048.

Eertwegh, V. V. D., Dalen, J. V., Dulmen, S. V., Vleuten, C. V. D., \& Scherpbier, A. (2014). Residents' perceived barriers to communication skills learning: comparing two medical working contexts in postgraduate training. Medical Education and Counseling, 95, 91-97.

Evans, D. E., Wood, D. F., \& Roberts, C. M. (2004). The effect of an extended hospital induction on perceived confidence and assessed clinical skills of newly qualified pre-registration house officers. Medical Education, 38: 998-1001. 


\section{REVIEW OF STUDIES ON ORAL CASE PRESENTATIONS IN CLINICAL SETTINGS}

Ford, S., Fallowfield, L., \& Lewis, S. (1996). Doctor-patient interactions in oncology. Society Science \& Medicine, 42(11): 1511-1519.

Green, E. H., Hershman, W., DeCherrie, L., Greenwald, J., Torres-Finnerty, HN., \& Wahi-Gururaj, S. (2005). Developing and implementing universal guidelines for oral patient presentation skills. Teaching and Learning in Medicine, 17(3): 263-268.

Guo, C. (1989). A report on the curriculum evaluation and development of foreign languages. Ching Chu: National Jiao Tong University.

Haber, R. J., \& Lingard, L. A. (2001). Learning oral presentation skills: a rhetorical analysis with pedagogical and professional implications. Journal of General Internal Medicine, 16: 308314.

Hung, H., Chen, P. C., \& Tsai, J. J. (2012). Rhetorical structure and linguistic features of case presentations in case reports in Taiwanese and international medical journals. Journal of English for Academic Purposes, 11, 220-228.

Hunter, K. M. (1991). Doctors' S tories: The Narrative Structure of Medical Knowledge. Princeton, N. J.: Princeton University Press.

Hwang, Y. L., \& Lin, S. (2010). A study of medical students' linguistic needs in Taiwan. The Asian ESP Journal, 6(1), 35-58.

Irby, D. M., Aagaard, E., \& Teherani, A. (2004). Teaching points identified by preceptors observing the one-minute preceptor and traditional preceptor encounters. Acad Med, 79, 50-55.

Ishikawa, H., Eto, M., Kitamura, K., Kiuchi, T. (2014). Resident physicians' attitudes and confidence in communicating with patients: a pilot study at a Japanese university hospital. Patient Education and Counseling, 96, 361-366.McCarthy, L. H., \& Reilly, E. H. (2000). How to write a case report. Family Medicine, 32(3): 190-195

Jian, H. (2010). The schematic structure of literature review in research articles of applied linguistics. Chinese Journal of Applied Linguistics (Bimonthly), 33(5): 15-27.

Johanson, M., Larsson, U. S., Saljo, R., \& Svardsudd, K. (1998). Lifestyle discussion in the provision of health case: an empirical study of patient-physician interaction. Society Science \& Medicine, 47(1): 103-112.

Kalitzkus, V., \& Matthiessen, P. F. (2012). Narrative-based medicine: potential, pitfalls, and practice. The Permanente Journal, 13(1): 80-86.

Khan, A. A., Zul Izhar Mohd Ismail, \& Aaijaz, N. (2009). Assessing the importance of communication skills in the education service sector with special reference to postgraduate medical students in Malaysia. JRMMR, 2(1): 87-94.

Kroenke, K. (1985). The case presentation: stumbling blocks and stepping stones. The American Journal of Medicine, 79(5): 605-608. 


\section{REVIEW OF STUDIES ON ORAL CASE PRESENTATIONS IN CLINICAL SETTINGS}

Lingard, L., \& Haber, R. J. (1999). What do we mean by "relevance"? A clinical and rhetorical definition with implications for teaching and learning the case-presentation format. Academic Medicine, 74(10): 124-127.

Lingard, L., Garwood, K., Schryer, C. F., \& Spafford, M. M. (2003a). A certain art of uncertainty: case presentation and the development of professional identity. Social Science and Medicine, 56(3): 603-616.

Lingard, L., Schryer, C., Garwood, K., \& Spafford, M. M. (2003b). Talking the talk: school and workplace genre tension in clerkship case presentations. Medical Education, 37(7): 612-620.

Maddow, C. L., Shah, M. N., Olsen, J., Cook, S., \& Howes, D. S. (2003). Efficient communication: assessment-oriented oral case presentation. Academic Emergency Medicine, 10(8): 842-847.

MAHEC. (n.d.). The Effective Preceptor. Retrieved from http://www.oucom.ohiou.edu/fd/monographs/effective.htm

Makoul, G., Krupat, E., Chang, C. (2007). Measuring patient views of physician communication skills: development and testing of the communication assessment tool. Patient Educ Couns, 67(3): 333-342.

Mead, N., \& Bower, P. (2000). Patient-centredness: a conceptual framework and review of the empirical literature. Social Science \& Medicine, 52, 1087-1110.

Mikel, J. T., McGuire, S. L., \& Gross-Gray, S. (2013). Grey's anatomy and communication accommodation: exploring aspects of nonverbal interactions portrayed in media. $A n$ International Journal on Personal Relationships, 7(1): 138-149.

Tavakol, M., Torabi, S., Lyne O. D., \& Zeinaloo, A. A. (2005). Quantitative survey of interns' knowledge of communication skills: an Iranian exploration. BMC Medical Education, 5(6). Retrieved from http://www.biomedcentral.com/content/pdf/1472-6920-5-6.pdf

Mott, Jr. T. (1986). Guidelines for writing case reports for the hypnosis literature. American Journal of Clinical Hypnosis, 29(1): 1-6.

Nwogu, K. N. (1997). The medical research paper: structure and functions. English for Specific Purposes, 16(2): 119-138.

Olson, D. P., \& Windish, D. M. (2010). Communication discrepancies between physicians and hospitalized patients. Arch Intern Med, 170(15): 1302-1307.

Rezaee, A. A., \& Sayfouri, N. (2009). Iranian ISI and non-ISI medical research articles in english: a comparative ESP/EAP move analysis. Journal of English Language Teaching and Learning, 52(212): 135-160.

Roberts, C., \& Sarangi, S. (2005). Theme-oriented discourse analysis of medical encounters. Medical Education, 39, 632-640. 


\section{REVIEW OF STUDIES ON ORAL CASE PRESENTATIONS IN CLINICAL SETTINGS}

Robins, L. S., \& Wolf, F. M. (1988). Confrontation and politeness strategies in physician-patient interactions. Social Science \& Medicine, 27(3): 217-221.

Salager-Meyer, F. (1992). A text-type and move analysis study of verb tense and modality distribution in medical English discourse: an investigation into genre analysis. System, 17(1): 21-34.

Salager-Meyer, F. (1994). Hedges and textual communicative function in medical English written discourse. English for Specific Purposes, 13(2): 149-170.

Salager-Meyer, F. (2001). From self-highlightedness to self-effacement: a genre-based study of the socio-pragmatic function of criticism in medical discourse. LSP \& Professional Communication: 1(2): 63-84.

Salam, A., Ahmad Faizal Mohd Perdaus, Siti Hamida Md Isa, Zulkifli Zainuddin, Azian Abdul Latiff, Ng Soon Pheng, Zauyah Yusuf, Soelaiman, I. N., Nabishah Mohamad, \& Norhayati Moktar. (2008). UKM medical graduates' perception of their communication skills during housemanship. Med \& Health, 3(1): 54-58.

Sami Abdo Rahman Al-Dubai, Redhwan Ahmed Al-Naggar, Mustafa Ahmed AlShagga, \& Krishna Gopal Rampal. (2011). Stress and coping strategies of students in a medical faculty in Malaysia. Malaysian J Med Sci, 18(3): 57-64.

Schryer, C. F., Lingard, L., Spafford, M., \& Garwood, K., (2003). Structure and agency in medical case presentations. Writing Selves/Writing Societies, Bazerman \& Russell, 62-96. Retrieved from http://wac.colostate.edu/books/selves_societies/

Schryer, C. F., Lingard, L., \& Spafford, M. M. (2005). Techne or artful science and the genre of case presentations in healthcare settings. Communication Monographs, 72(2): 234-260.

Shi, L., Corcos, R., \& Storey, A. (2001). Using student performance data to develop an English course for clinical training. English for Specific Purposes, 20(3): 267-291.

Spafford, M. M., Lingard, L., Schryer, C.F., \& Hrynchak, P.K. (2004). Tensions in the field: teaching standards of practice in optometry case presentations. Optometry and Vision Science, 81(10): 800-806.

Spafford, M. M., Schryer, C. F., Campbell, S. L., \& Lingard, L. (2007). Towards embracing clinical uncertainty: lessons from social work, optometry and medicine. Journal of Social Work, 7 , $155-178$.

Stausmire, J. M., Cashen, C. P., Myerholtz, L., \& Buderer, N. (in press). Measuring general surgery residents' communication skills from the patient's perspective using the communication assessment tool (CAT). Journal of Surgical Education. Retrieved from http://www.sciencedirect.com/science/article/pii/S1931720414001998

Sutton, B. (2000). Swales's “moves” and the research paper assignment. TETYC, 27(4): 446-451.

Swales, J. M. (1990). Genre Analysis : English in academic and research settings. Cambridge : Cambridge University. 


\section{REVIEW OF STUDIES ON ORAL CASE PRESENTATIONS IN CLINICAL SETTINGS}

Tarn, D. M., Heritage, J., Paterniti, D. A., Hays, R. D., Kravitz, R. L., \& Wenger, N. S. (2006). Physician communication when prescribing new medications. Arch Intern Med, 166, 18551862.

Thomas, S., \& Hawes, T. P. (1994). Reporting verbs in medical journal articles. English for Specific Purposes, 13(2): 129-148.

Ullah, M. A., Barman, A., Ahmad Fuad Abdul Rahim, \& Muhamad Saiful Bahri Yusoff. (2012). Validity of communication skills attitude scale among Malaysian medical students. South East Asian Journal of Medical Education, 6(1): 10-13.

Varttala, T. (1999). Remarks on the communicative functions of hedging in popular scientific and specialist research articles on medicine. English for Specific Purposes, 18(2): 177-200.

Wiese, J., Saint, S., \& Tierney, L. M. (2002). Using clinical reasoning to improve skills in oral case presentation. Seminars in Medical Practice, 5(3): 39-36.

Wiese, J., Varosy, P., \& Tierney, L. (2002). Improving oral presentation skills with a clinical reasoning curriculum: a prospective controlled study. The American Journal of Medicine, 112: 212-218.

Wolpaw, T. M., Wolpaw, D. R., \& Papp, K. K. (2003). SNAPPS: a learner-centered model for outpatient education. Acad Med, 78: 893-898.

Wright, S. M., \& Kouroukis, C. (2000). Capturing zebras: what to do with a reportable case. Canadian Medical Association Journal, 163(4): 429-431.

Zughoul, M. R., \& Hussein, R. F. (1985). English for higher education in the Arab world: a case study of needs of analysis of Yarmouk University. English for Specific Purposes Journal, 4, 133-152. 